\title{
Developmental Pharmacogenetics of SLCO2BI on Montelukast Pharmacokinetics in Chinese Children
}

This article was published in the following Dove Press journal:

Drug Design, Development and Therapy

\section{Qian Li, ${ }^{1,2, *}$ Kai Wang, ${ }^{3, *}$ Hai-Yan Shi, ${ }^{2}$ Yue-E Wu, 'Yue Zhou,' Min Kan,' Yi Zheng,' Guo-Xiang Hao,' Xin-Mei Yang, ${ }^{2}$ Yi-Lei Yang, ${ }^{2}$ Le-Qun $\mathrm{Su}^{2}{ }^{2}$ Xiao-Ling Wang, ${ }^{4}$ Evelyne Jacqz-Aigrain, ${ }^{5,6}$ Jun Zhou, ${ }^{7, *}$ Wei Zhao (iD) ${ }^{1,2, *}$}

'Department of Clinical Pharmacy, School of Pharmaceutical Sciences, Shandong University, Jinan, People's Republic of China ${ }^{2}$ Department of Pharmacy, Shandong Provincial Qianfoshan Hospital, The First Affiliated Hospital of Shandong First Medical University, Jinan, People's Republic of China;

${ }^{3}$ Department of Respiratory Disease,

Shandong Provincial Qianfoshan Hospital,

The First Affiliated Hospital of Shandong

First Medical University, Jinan, People's

Republic of China; ${ }^{4}$ Clinical Research

Center, Beijing Children's Hospital, Capital

Medical University, National Center for

Children's Health, Beijing, People's Republic

of China; ${ }^{5}$ Department of Pediatric

Pharmacology and Pharmacogenetics, Hôpital Robert Debré, AP-HP, Paris, France; ${ }^{6}$ University Paris Diderot, Sorbonne ParisCité, Paris, France; ${ }^{7}$ Clinical Training Center, Shandong Provincial Qianfoshan Hospital, The First Affiliated Hospital of Shandong First Medical University, Jinan, People's Republic of China

*These authors contributed equally to this work

Correspondence: Jun Zhou

Clinical Training Center, Shandong Provincial Qianfoshan Hospital, The First Affiliated Hospital of Shandong First Medical University, 16766 Jing Shi Street, Jinan 250014, People's Republic of China Tel/Fax +86 53I 82373200

Email zhoujun_jn@I63.com

Wei Zhao

Department of Clinical Pharmacy, School of Pharmaceutical Sciences, Shandong University, 44 Culture West Road, Jinan 2500 12, People's Republic of China $\mathrm{Tel} / \mathrm{Fax}+8653188383308$

Email zhao4wei@hotmail.com
Background: Montelukast, a potent oral selective leukotriene-receptor antagonist, inhibits the action of cysteinyl-leukotriene in patients with asthma. Although pharmacokinetic studies of montelukast have been reported in Caucasian adults and children, and showed large interindividual variability on pharmacokinetics, none of these studies has been explored in Chinese children. Given the potential inter-ethnic difference, the purpose of the present study was to evaluate the effects of developmental factors and pharmacogenetics of CYP2C8 and SLCO2B1 on montelukast clearance in Chinese pediatric patients.

Methods: After the administration of montelukast, blood samples were collected from children and plasma concentrations were determined using an adapted micro highperformance liquid chromatography coupled with the fluorescence detection (HPLC-FLD) method. A previously published pharmacokinetic model was validated using the opportunistic pharmacokinetic samples, and individual patient's clearance was calculated using the validated model. Population pharmacokinetic analysis was performed using a nonlinear mixed-effects model approach (NONMEM V 7.2.0) and variants of CYP2C8 and SLCO2B1 were genotyped.

Results: Fifty patients (age range: $0.7-10.0$ years) with asthma were enrolled in this study. The clearance of montelukast was significantly higher in children with the SLCO2B1 c.935GA and c.935AA genotypes compared with that of children with the SLCO2B1 c.935GG genotype $(0.94 \pm 0.26$ versus $0.77 \pm 0.21, \mathrm{p}=0.020)$. The patient's weight was also found to be significantly corrected with montelukast clearance $(\mathrm{p}<0.0001)$.

Conclusion: The developmental pharmacology of montelukast in Chinese children was evaluated. Weight and SLCO2B1 genotype were found to have independent significant impacts on the clearance of montelukast.

Keywords: montelukast, ontogeny, pharmacogenetics, children

\section{Introduction}

Montelukast is a selective leukotriene-receptor antagonist (LTRA) that blocks the action of cysteinyl leukotrienes, and its efficacy in the control of symptoms associated with asthma has been previously demonstrated in adults ${ }^{1}$ and children. $^{2-5}$ Convenience in administration (once-daily), good tolerance and improved adherence make montelukast a good option for monotherapy or as an add-on therapy of asthma in pediatric patients. ${ }^{6}$ Currently, the $4 \mathrm{mg}$ (granules or chewable tablet) and $5 \mathrm{mg}$ (chewable tablets) dose formulations have been identified as a prophylactic or long-term treatment option for asthma in children.

Montelukast is absorbed well after oral administration, and oral bioavailability (chewable tablets) is approximately $73 \% .^{7}$ Moreover, montelukast undergoes 
extensive metabolism and a majority of the metabolites are excreted through bile. Previous studies have shown that the enzymes of cytochrome P450 (CYP) 2C8, 2C9, 3A4 and uridine diphosphate-glucuronosyltransferase (UGT) $1 \mathrm{~A} 3$ are involved in the metabolism of montelukast. ${ }^{8-12}$ Meanwhile, some reports have suggested that the organic anion transporting polypeptide (OATP) 1B1, 1B3, and 2B1 transporters play a part in the permeability of montelukast. ${ }^{13,14}$

In clinical practice, the effectiveness of montelukast shows large inter-individual variability. ${ }^{15,16}$ Variations among genes encoding the metabolizing enzymes or membrane transporters ${ }^{8-11,13,14,17}$ were correlated with the clinical response to montelukast. ${ }^{18,19}$ For infants and children, the disposition of the drug is influenced by developmental changes in the body, such as organ maturation and function, as well as composition and amount of plasma proteins. ${ }^{20}$ Meanwhile, age-dependent changes in gastric emptying, intestinal enzyme activity and transporters in infants and children may also alter the bioavailability of a drug. ${ }^{21}$ In addition, some studies have suggested that CYP2C8 played an important role in the metabolism of montelukast; ${ }^{8-10}$ several other studies have demonstrated that a common polymorphism of SLCO2B1, the gene coding for the OATP2B1 transport protein, exhibited a substantial effect on the pharmacokinetics and pharmacodynamics of montelukast. ${ }^{13,17}$ Recently, a study reported that the pharmacokinetics of montelukast was determined by OATPs-mediated uptake, along with CYP2C8 metabolism. ${ }^{14}$ It should be noted that all these pharmacogenetic studies have been conducted in Caucasian adults. Given the impact of ontogeny and potential inter-ethnic difference, the objective of the present study was to evaluate the ontogeny and pharmacogenetic effects of CYP2C8 and SLCO2B1 on montelukast clearance in Chinese pediatric patients.

\section{Methods}

\section{Subjects}

The study was designed as a prospective, open-label pharmacokinetic-pharmacogenetic trial and was carried out at Shandong Provincial Qianfoshan Hospital. Patients aged between 6 months and 12 years, with a history of asthma or asthma-like symptoms (including but not limited to wheezing, cough and shortness of breath) who underwent routine treatment with montelukast were chosen for the study. Patients were excluded if they had been enrolled in another clinical trial, had other serious diseases or had been co-administrated with known inhibitors or inducers of CYP2C8 and SLCO2B1. The study protocol was approved by the ethics committees of the clinical institution (Shandong Provincial Qianfoshan Hospital). A written informed consent was obtained from the parents or guardians of the patients, prior to the initiation of the study. This trial was conducted in accordance with the Declaration of Helsinki. The Clinical Trial registration number is NCT03238560.

\section{Dosage Regimen and Blood Sampling}

Four milligram (0.5-5years) and $5 \mathrm{mg}$ (6-12years) doses of chewable montelukast tablets (Singulair ${ }^{\mathrm{TM}}$, Merck Sharp \& Dohme Limited, USA) were administered oncedaily at bedtime without food. Since the volume of blood that could be obtained from individual participants was limited, an opportunistic sampling design was chosen for the collection of pharmacokinetic samples. ${ }^{22}$ Precise drug administration time and sampling time were recorded. A blood volume of $200 \mu \mathrm{L}$ per sample was obtained at the steady-state condition from each patient for concentration determination. After centrifugation (4000 rpm, 10 min), the plasma samples were stored at $-80^{\circ} \mathrm{C}$ and protected from light until analysis.

\section{Determination of Montelukast}

Montelukast plasma concentration was measured using a micro high-performance liquid chromatography with fluorescence detention (HPLC-FLD). Mefenamic acid was used as an internal standard. The standard of montelukast (lot numbers M568000) was purchased from the Toronto Research Chemicals (North York, Canada). The internal standard of mefenamic acid (lot number 100190-200903) was purchased from National Institutes for Food and Drug Control (Beijing, China). HPLC-grade acetonitrile was obtained from Sigma-Aldrich (St Louis, MO, USA). The sodium acetate trihydrate, triethylamine and glacial acetic acid were obtained from Sinopharm Chemical Reagent (Shanghai, China). HPLC separation is achieved on C18 column connected to a fluorescent detector with an excitation wavelength of $350 \mathrm{~nm}$ and emission wavelength of 400nm, using acetonitrile and water $(3.4 \mathrm{~g} / \mathrm{L}$ sodium acetate trihydrate, $0.005 \%$ triethylamine, $\mathrm{pH} 4.0$ ) in a gradient mode of elution at a flow rate of $1.0 \mathrm{~mL} / \mathrm{min}$ at $40^{\circ} \mathrm{C}$. Acetonitrile was used to precipitate protein during the plasma extraction procedures. The recovery is $87.2 \%$. The lower limit of quantification (LLOQ) of montelukast was $1.0 \mathrm{ng} / \mathrm{mL}$. The calibration 
curve used in this study stretched over a range of 1.0-2000 $\mathrm{ng} / \mathrm{mL}$. The intra- and inter-day coefficients of variation (CVs) were assessed using quality control (QC) samples and were found to be $3.58 \%$ and $4.02 \%$, respectively.

\section{Genotyping}

Isolation of DNA from blood was performed through standard methods using the TIANamp Blood DNA Kit (TIANGEN Biotech, Beijing, China). The single nucleotide polymorphisms (SNPs) of CYP2C8*1B (rs7909236) and SLCO2B1 c.935G $>$ A (rs12422149) were selected for genotyping. Polymerase chain reaction (PCR) was performed on a Fluorescence Quantitative PCR (Bio-Rad, Hercules, CA, USA) using TaqMan ${ }^{\circledR}$ Universal PCR Master Mix and probes (Thermo Fisher Scientific, MA, USA).

\section{Pharmacokinetic Analysis}

Pharmacokinetic parameters were calculated using NONMEM software (ver. 7.2.0, Icon Development Solutions, Ellicott City, MD, USA). An external validation of the previously published model in children was performed at the first step; then, the validated model was used to derive individual clearance of montelukast for the following pharmacogenetic analysis. A linear threecompartment pharmacokinetic model ${ }^{23}$ with $73 \%$ bioavailability of the chewable tablets ${ }^{7}$ and a constant absorption rate $(\mathrm{Ka})$ of $0.5 \mathrm{~L} / \mathrm{h}^{24}$ was evaluated. The following modeling information was extracted from the published article: interindividual variability for clearance (CL), central compartment volume of distribution $(\mathrm{Vc})$ and peripheral volume of distribution ( $\mathrm{Vp})$ (\% coefficient of variation [\%CV], $24.2 \%, 14.0 \%$ and $45.4 \%$, respectively) by exponential error model, residual variability using a combined additive and proportional model $(\% \mathrm{CV}, 3.7 \mathrm{ng} / \mathrm{mL}$ and $10.4 \%)$ and a significant influence of current weight $(\mathrm{CW})$ on $\mathrm{CL}$ and $\mathrm{V}_{\mathrm{c}}, \mathrm{V}_{\mathrm{P} 1}, \mathrm{~V}_{\mathrm{P} 2}, \mathrm{Q}_{1}, \mathrm{Q}_{2}$ with the following regression equations (equations 1-6):

$$
\begin{gathered}
\mathrm{CL}=0.175 \times \mathrm{CW}^{\wedge} 0.635 \text { liters } / \mathrm{h} \\
\mathrm{V}_{\mathrm{c}}=0.156 \times \mathrm{CW}^{\wedge} 0.726 \text { liters } \\
\mathrm{V}_{\mathrm{p} 1}=2.18 \text { liters } \\
\mathrm{V}_{\mathrm{p} 2}=2.61 \text { liters } \\
\mathrm{Q}_{1}=0.256 \text { liters } / \mathrm{h}
\end{gathered}
$$

$$
\mathrm{Q}_{2}=2.58 \text { liters } / \mathrm{h}
$$

The individual concentrations were predicted by Bayesian estimation (MAXEVAL $=0$ in the estimation step, where MAXEVAL is the maximum number of model evaluations that can be used) with NONMEM using the population pharmacokinetic parameters.

\section{Statistical Analysis}

Statistical analyses were performed using SPSS statistical software version 16.0 (IBM SPSS Statistics, IBM Inc., NY, USA). The Hardy-Weinberg equilibrium was verified for CYP2C8*1B (rs7909236) and SLCO2B1 c.935G $>$ A (rs12422149) genotypes. The medians and ranges of continuous variables were summarized, and linear regression analysis was carried out. Frequencies and proportions were used to summarize categorical variables, while the MannWhitney $U$-test was used to compare the variance between groups (patients with homozygous wild-type alleles and patients with heterozygotes and homozygous alleles). Multiple linear regression analysis with entry criteria of 0.20 and exit criteria of 0.05 in a stepwise selection method was performed to determine the association between multiple factors and montelukast clearance.

\section{Results}

Fifty patients were enrolled in this study. All patients met the inclusion and exclusion criteria and written informed consent for their participation was obtained. Eight patients use montelukast as monotherapy and 42 patients with comedication of loratadine. No drug-related adverse events were shown to have a causal association with Montelukast therapy. The mean (standard deviation) age was 4.4 (2.4) (range 0.7-10.0) years and the mean (standard deviation) weight was 19.9 (8.4) (range 7.0-49.0) kilograms. The characteristics of patients are summarized and presented in Table 1. The opportunistic sampling time ranged from 0.5 to $24.8 \mathrm{hrs}$ post-dose. The external validation of the developed model showed a good predictive performance (Figure 1). The average prediction bias was $7.1 \%$, and $74.1 \%$ of the measurements were within $\pm 50 \%$ of the prediction error.

All 50 patients who participated in the study were genotyped for CYP2C8*1B g.-271C $>$ A (rs7909236) and SLCO2B1 c.935G $>$ A (rs12422149) polymorphism. The frequencies of CYP2C $8 * 1 \mathrm{~B}$ and SLCO2B1 c. $935 \mathrm{G}>\mathrm{A}$ were $8.0 \%$ and $58.0 \%$, respectively. For CYP2C $8 * 1 \mathrm{~B}$, the frequency is comparable to that of published data in Chinese 
Table I Characteristics of the 50 Children

\begin{tabular}{|l|l|l|l|}
\hline Patient Characteristics & Number & Mean (SD) & Median (Range) \\
\hline Patients & 50 & & \\
\hline Gender & $24 \mathrm{M} / 26 \mathrm{~F}$ & & \\
\hline Age (years) & & $4.4(2.4)$ & $4.0(0.7-10.0)$ \\
\hline Body weight (kg) & & $19.9(8.4)$ & $17.8(7.0-49.0)$ \\
\hline Montelukast dose (mg) & & $5.0(0.19)$ & $5.0(4.0-5.0)$ \\
\hline $\begin{array}{l}\text { Montelukast concentrations } \\
\text { (ng/mL) }\end{array}$ & & $181.7(172.4)$ & $123.3(12.9-769.9)$ \\
\hline Montelukast clearance (L/h) & & $0.87(0.25)$ & $0.83(0.5-1.5)$ \\
\hline Genotype & & No. (frequency) \\
\hline CYP2C8*IB g.-27IC>A & CC & $46(92.0 \%)$ \\
\hline & CA & $4(8.0 \%)$ \\
\hline & AA & $0(0 \%)$ \\
\hline SLCO2BI c.935G>A & GG & $21(42.0 \%)$ \\
\hline & GA & $24(48.0 \%)$ \\
\hline & AA & $5(10.0 \%)$ \\
\hline
\end{tabular}

Notes: Gender: $M$ for male, $F$ for female; range: minimum value-maximum Value.

populations. ${ }^{25}$ All genotypes were in Hardy-Weinberg equilibrium. The results are summarized in Table 1.

The pharmacokinetics of montelukast was found to be significantly correlated with SLCO2B1 genotype. Montelukast clearance was significantly higher in SLCO2B1 c.935GA and c.935AA subjects compared with that of SLCO2B1 c. $935 \mathrm{GG}$ subjects $(0.94 \pm 0.26$ versus 0.77 \pm 0.21 , Mann-Whitney $U$-test, $\mathrm{p}=0.020$ ) (Figure 2). Weight

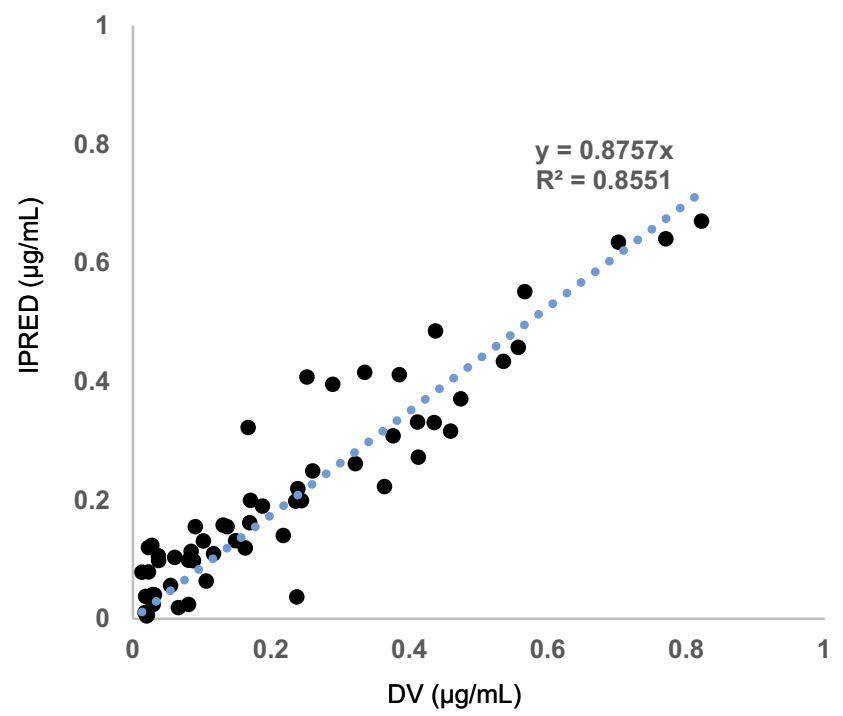

Figure I External validation of the published model. X-axis: DV observed concentrations $(\mu \mathrm{g} / \mathrm{mL})$. Y-axis: IPRED individual predicted concentrations $(\mu \mathrm{g} / \mathrm{mL})$.

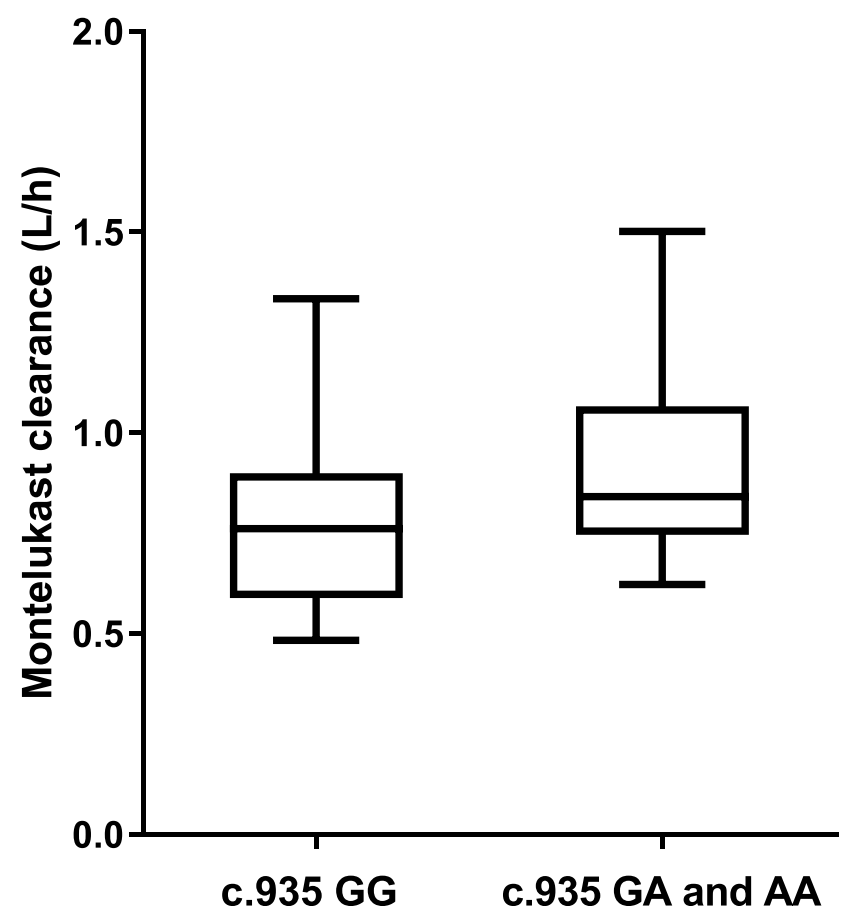

Figure 2 Relationship between SLCO2BI genotype and Montelukast clearance (n $=50, p=0.020)$. X-axis: SLCO2BI genotype (c.935GG vs c.935GA and c.935AA). Y-axis: Montelukast clearance $(\mathrm{L} / \mathrm{h})$.

was also found to be significantly correlated with montelukast clearance ( $\mathrm{p}<0.0001)$ (Figure 3). In final, multiple linear regression analyses revealed that the distinctive factors that are associated with montelukast clearance include weight $(\mathrm{p}=0.035)$ and SLCO2B1 c.935G $>$ A genotype $(\mathrm{p}=$ $0.045)$. These two factors could explain about $44.1 \%$ of the variability in montelukast clearance $\left(\mathrm{R}^{2}=0.464\right)$. Weight and SLCO2B1 genotype explained $60.2 \%$ and $24.9 \%$ strength of

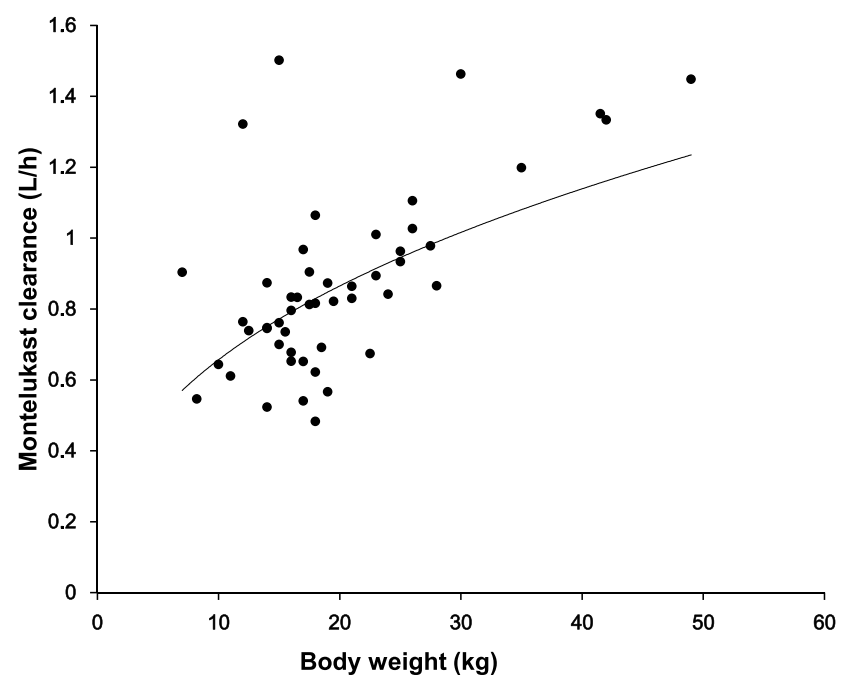

Figure 3 Relationship between body weight and Montelukast clearance ( $n=50$, $\mathrm{p}<0.000 \mathrm{I})$. X-axis: Body weight $(\mathrm{kg})$. Y-axis: Montelukast clearance (L/h). 
Table 2 Comparison Between SLCO2BI Genotypes Groups

\begin{tabular}{|l|l|l|l|}
\hline & $\begin{array}{l}\text { SLCO2B I } \\
\text { c.935 GG }\end{array}$ & $\begin{array}{l}\text { SLCO2B I } \\
\text { C.935GA and AA }\end{array}$ & P \\
\hline $\begin{array}{l}\text { Age (years) } \\
\text { Mean } \pm \text { SD }\end{array}$ & $3.7 \pm 1.79$ & $4.9 \pm 2.63$ & 0.10 \\
\hline $\begin{array}{c}\text { Body weight (kg) } \\
\text { Mean } \pm \text { SD }\end{array}$ & $18.6 \pm 7.51$ & $20.8 \pm 8.98$ & 0.36 \\
\hline $\begin{array}{l}\text { Gender } \\
\text { Male } \\
\text { Female }\end{array}$ & 14 & 12 & 0.09 \\
\hline $\begin{array}{l}\text { Montelukast dose } \\
\text { (mg) } \\
4 \text { mg } \\
5 \text { mg }\end{array}$ & 7 & 17 & 0.17 \\
\hline $\begin{array}{l}\text { Combined therapy } \\
\text { Co-medication } \\
\text { with loratadine } \\
\text { Montelukast alone }\end{array}$ & 3 & 29 & 1.0 \\
\hline
\end{tabular}

association, respectively. The two SLCO2B1 genotype groups are comparable in terms of age, weight, dose and cotreatment (Table 2).

\section{Discussion}

The developmental pharmacogenetics of montelukast was evaluated for the first time in Chinese children. The independent impacts of weight and SLCO2B1 genotype on montelukast clearance were demonstrated.

In our present study, montelukast clearance showed considerable inter-individual variability that may partly be due to the variants of SLCO2B1 c.935G>A genotypes among patients. Our findings suggest that SLCO2B1 c. $935 \mathrm{G}>\mathrm{A}$ genetic polymorphism has a significant influence on montelukast clearance, and that the mean clearance increased by $22.1 \%$ in c.935GA and c.935AA groups compared with that of the c. $935 \mathrm{GG}$ group. The increase in montelukast clearance is reflected through lower concentrations of montelukast, resulting in decreased AUC. This result is consistent with previous studies on adults. ${ }^{13,17}$ In addition, previous data indicated that subjects with the c. $935 \mathrm{GG}$ genotype had a better clinical response in montelukast add-on therapy compared with those with the c.935GA and c.935AA genotypes, after one and six months of therapy, respectively. ${ }^{13}$ The present results showed that subjects with c.935GA and c.935AA genotypes had lower plasma levels of montelukast, which may result in poor efficacy, and this factor should be considered in order to optimize the dosing of montelukast during therapy. Some previous studies showed a negative impact of SLCO2B1 polymorphisms on the pharmacokinetics of montelukast. ${ }^{26,27}$ The reasons for this discrepancy can be speculated as follows. As shown in Table 1, the allele frequency of c. $935 \mathrm{G}>\mathrm{A}$ in the Chinese population is $58.0 \%$, which is higher than that in other ethnic groups: $8.18 \%$ for Caucasians, $13.6 \%$ for African-Americans, ${ }^{17} 13.2 \%$ for Finnish $^{26}$ and $42.7 \%$ for Koreans. ${ }^{27}$ Furthermore, the number of participants in previous studies was between 24 and 33 individuals. Therefore, it can be ruled out that a limited number of participants may have yielded falsenegative results.

In addition to the SLCO2B1 c. $935 \mathrm{G}>\mathrm{A}$ polymorphism, we also evaluated CYP2C8 polymorphism. The results showed no effect of CYP2C8 polymorphism on Montelukast clearance was detected, even though it was estimated that $80 \%$ of the montelukast metabolism is mediated by CYP2C $8 .^{9}$ Previous studies have suggested that CYP2C8, especially CYP2C $8 * 3$ and CYP2C $8 * 4$ alleles, play an important role in the inter-individual variability of many drugs. ${ }^{25,28,29}$ However, the approximate allele frequencies of CYP2C $8 * 3$ and CYP2C $8 * 4$ in Han Chinese are nearly zero. For CYP2C $8 * 1 B$ (rs7909236), the allele frequency in our study was found to be only $8 \%$, which is lower than that in Caucasians $(24 \%){ }^{30}$ Moreover, it has been suggested that except for an increase in promoter activity and transcription factor binding, there was no difference in protein expression between CYP2C $8 * 1 \mathrm{~B}$ variant allele and wild-type allele. ${ }^{25,30}$ These factors may explain why CYP2C8 variants were not found to be significantly associated with montelukast clearance.

The impact of weight on montelukast clearance is in agreement with the results of a previous pharmacokinetic study in children. ${ }^{23}$ The clearance of montelukast increased allometrically along with body weight.

However, there are some limitations in our present study. Since the primary objective was to evaluate the ontogeny and pharmacogenetic effects of CYP2C8 and SLCO2B1 on montelukast pharmacokinetics in Chinese pediatric patients, the effectiveness was not evaluated. In addition, the unexplained variability in our study is still large, indicating that other covariates still contribute to the pharmacokinetics of montelukast. These missing covariates also require further evaluation. 
In conclusion, the developmental pharmacogenetics of montelukast in Chinese children was evaluated. Weight and SLCO2B1 genotype were found to have independent significant impacts on the montelukast clearance. Our results emphasize the importance of evaluating the developmental pharmacology of montelukast in inter-ethnic populations.

\section{Data Sharing Statement}

The pharmacogenetic data can be shared by emailing requests to the corresponding author.

\section{Acknowledgments}

The abstract of this paper was presented at the European Society for Developmental Perinatal and Paediatric Pharmacology Congress as a poster presentation with interim findings. The poster's abstract was published in "Poster Abstracts" in Archives of Disease in Childhood.

\section{Funding}

This study was supported by National Science and Technology Major Project for Major New Drugs Innovation and Development (2017ZX09304029-001; 2017ZX09304029-002), Young Taishan Scholars Program of Shandong Province and Qilu Young Scholars Program of Shandong University.

\section{Disclosure}

WZ reports grants from the National Science and Technology Major Project for Major New Drugs Innovation and Development, the Young Taishan Scholars Program of Shandong Province, and the Qilu Young Scholars Program of Shandong University, during the conduct of the study. The authors report no other conflicts of interest in this work.

\section{References}

1. Reiss TF, Chervinsky P, Dockhorn RJ, et al. Montelukast, a once-daily leukotriene receptor antagonist, in the treatment of chronic asthma: a multicenter, randomized, double-blind trial. Montelukast Clinical Research Study Group. Arch Intern Med. 1998;158:1213-1220. doi:10.1001/archinte.158.11.1213

2. Knorr B, Larson P, Nguyen HH, et al. Montelukast dose selection in 6to 14-year-olds: comparison of single-dose pharmacokinetics in children and adults. J Clin Pharmacol. 1999;39:786-793. doi:10.1177/ 00912709922008434

3. Knorr B, Nguyen HH, Kearns GL, et al. Montelukast dose selection in children ages 2 to 5 years: comparison of population pharmacokinetics between children and adults. J Clin Pharmacol. 2001;41:612-619. doi:10.1177/00912700122010492
4. Migoya E, Kearns GL, Hartford A, et al. Pharmacokinetics of montelukast in asthmatic patients 6 to 24 months old. J Clin Pharmacol. 2004;44:487-494. doi:10.1177/0091270004264970

5. Knorr B, Maganti L, Ramakrishnan R, et al. Pharmacokinetics and safety of montelukast in children aged 3 to 6 months. J Clin Pharmacol. 2006;46:620-627. doi:10.1177/0091270006288324

6. Muijsers RB, Noble S. Montelukast: a review of its therapeutic potential in asthma in children 2 to 14 years of age. Paediatr Drugs. 2002;4:123-139. doi:10.2165/00128072-200204020-00005

7. Knorr B, Holland J, Schwartz J. Clinical pharmacology of montelukast. Clin Exp Allergy Rev. 2001;1:254-260. doi:10.1046/ j.1472-9725.2001.t01-1-00011.x

8. Filppula AM, Laitila J, Neuvonen PJ, et al. Reevaluation of the microsomal metabolism of montelukast: major contribution by CYP2C8 at clinically relevant concentrations. Drug Metab Dispos. 2011;39:904-911. doi:10.1124/dmd.110.037689

9. Karonen T, Neuvonen PJ, Backman JT. CYP2C8 but not CYP3A4 is important in the pharmacokinetics of montelukast. $\mathrm{Br} J$ Clin Pharmacol. 2012;73:257-267. doi:10.1111/j.1365-2125.2011.04086.x

10. Cardoso Jde O, Oliveira RV, Lu JB, et al. In vitro metabolism of montelukast by cytochrome P450s and UDP-glucuronosyltransferases. Drug Metab Dispos. 2015;43:1905-1916. doi:10.1124/dmd.115.065763

11. Chiba M, Xu X, Nishime JA, et al. Hepatic microsomal metabolism of montelukast, a potent leukotriene D4 receptor antagonist, in humans. Drug Metab Dispos. 1997;25:1022-1031.

12. Hirvensalo P, Tornio A, Neuvonen $M$, et al. Comprehensive pharmacogenomic study reveals an important role of UGT1A3 in montelukast pharmacokinetics. Clin Pharmacol Ther. 2018;104:158-168. doi:10.1002/cpt.v104.1

13. Mougey EB, Feng H, Castro M, et al. Absorption of montelukast is transporter mediated: a common variant of OATP2B1 is associated with reduced plasma concentrations and poor response. Pharmacogenet Genomics. 2009;19:129-138. doi:10.1097/FPC.0b013e32831bd98c

14. Varma MV, Kimoto E, Scialis R, et al. Transporter-mediated hepatic uptake plays an important role in the pharmacokinetics and drug-drug interactions of montelukast. Clin Pharmacol Ther. 2017;101: 406-415. doi:10.1002/cpt.v101.3

15. Lima JJ. Treatment heterogeneity in asthma: genetics of response to leukotriene modifiers. Mol Diagn Ther. 2007;11:97-104. doi:10. 1007/BF03256228

16. Weiss ST, Litonjua AA, Lange C, et al. Overview of the pharmacogenetics of asthma treatment. Pharmacogenomics J. 2006;6:311-326. doi:10.1038/sj.tpj.6500387

17. Mougey EB, Lang JE, Wen X, et al. Effect of citrus juice and SLCO2B1 genotype on the pharmacokinetics of montelukast. J Clin Pharmacol. 2011;51:751-760. doi:10.1177/0091270010374472

18. Telleria JJ, Blanco-Quiros A, Varillas D, et al. ALOX5 promoter genotype and response to montelukast in moderate persistent asthma. Respir Med. 2008;102:857-861. doi:10.1016/j.rmed.2008.01.011

19. Tantisira KG, Lima J, Sylvia J, et al. 5-lipoxygenase pharmacogenetics in asthma: overlap with Cys-leukotriene receptor antagonist loci. Pharmacogenet Genomics. 2009;19:244-247. doi:10.1097/ FPC.0b013e328326e0b1

20. Kearns GL, Abdel-Rahman SM, Alander SW, et al. Developmental pharmacology-drug disposition, action, and therapy in infants and children. $N$ Engl J Med. 2003;349:1157-1167. doi:10.1056/NEJMra035092

21. Kearns GL, Lu S, Maganti L, et al. Pharmacokinetics and safety of montelukast oral granules in children 1 to 3 months of age with bronchiolitis. J Clin Pharmacol. 2008;48:502-511. doi:10.1177/ 0091270008314251

22. Leroux S, Turner MA, Guellec CB, et al. Pharmacokinetic studies in neonates: the utility of an opportunistic sampling design. Clin Pharmacokinet. 2015;54:1273-1285. doi:10.1007/s40262-015-0291-1

23. Ramakrishnan R, Migoya E, Knorr B. A population pharmacokinetic model for montelukast disposition in adults and children. Pharm Res. 2005;22:532-540. doi:10.1007/s11095-005-2493-y 
24. Zhou W, Johnson TN, Bui KH, et al. Predictive Performance of Physiologically Based Pharmacokinetic (PBPK) modeling of drugs extensively metabolized by major cytochrome P450s in children. Clin Pharmacol Ther. 2018;104:188-200. doi:10.1002/cpt.v104.1

25. Aquilante CL, Niemi M, Gong L, et al. PharmGKB summary: very important pharmacogene information for cytochrome P450, family 2, subfamily C, polypeptide 8. Pharmacogenet Genomics. 2013;23: 721-728. doi:10.1097/FPC.0b013e3283653b27

26. Tapaninen T, Karonen T, Backman JT, et al. SLCO2B1 c.935G $>$ A single nucleotide polymorphism has no effect on the pharmacokinetics of montelukast and aliskiren. Pharmacogenet Genomics. 2013;23:19-24. doi:10.1097/FPC.0b013e32835bac90

27. Kim KA, Lee HM, Joo HJ, et al. Effects of polymorphisms of the SLCO2B1 transporter gene on the pharmacokinetics of montelukast in humans. J Clin Pharmacol. 2013;53:1186-1193. doi:10.1002/jcph.144
28. Bahadur N, Leathart JB, Mutch E, et al. CYP2C8 polymorphisms in Caucasians and their relationship with paclitaxel 6alpha-hydroxylase activity in human liver microsomes. Biochem Pharmacol. 2002;64:1579-1589. doi:10.1016/S0006-2952(02)01354-0

29. Tornio A, Niemi M, Neuvonen PJ, et al. Trimethoprim and the CYP2C8*3 allele have opposite effects on the pharmacokinetics of pioglitazone. Drug Metab Dispos. 2008;36:73-80. doi:10.1124/ dmd.107.018010

30. Rodriguez-Antona C, Niemi M, Backman JT, et al. Characterization of novel CYP2C8 haplotypes and their contribution to paclitaxel and repaglinide metabolism. Pharmacogenomics J. 2008;8:268-277. doi:10.1038/sj.tpj.6500482

\section{Publish your work in this journal}

Drug Design, Development and Therapy is an international, peerreviewed open-access journal that spans the spectrum of drug design and development through to clinical applications. Clinical outcomes, patient safety, and programs for the development and effective, safe, and sustained use of medicines are a feature of the journal, which has also been accepted for indexing on PubMed Central. The manuscript management system is completely online and includes a very quick and fair peer-review system, which is all easy to use. Visit http://www. dovepress.com/testimonials.php to read real quotes from published authors. 